\title{
Sugammadex Development and Use in Clinical Practice
}

\author{
Claude Meistelman • Thomas Fuchs-Buder • \\ Julien Raft
}

Published online: 19 March 2013

(C) Springer Science + Business Media New York 2013

\begin{abstract}
Sugammadex belongs to a new class of drug: the selective relaxant binding agents. Sugammadex can reverse residual paralysis by encapsulating free circulating nondepolarizing muscle relaxants. The main advantages of sugammadex when compared with conventional anticholinesterase agents are a much faster recovery time and the unique ability, for the first time, to reverse rapidly and efficiently deep levels of neuromuscular blockade. However, it only works for reversal of rocuronium- or vecuroniuminduced neuromuscular blockade. When administered $3 \mathrm{~min}$ after rocuronium, the use of a large dose $(16 \mathrm{mg} / \mathrm{kg})$ can even reverse rocuronium significantly faster than the spontaneous recovery after succinylcholine. Compared with neostigmine, reversal cost is significantly higher. However, economic aspects must take into account the reduction in recovery time and, more importantly, the prevention of residual paralysis in the PACU that can induce critical respiratory events and postoperative pulmonary complications.
\end{abstract}

Keywords Cyclodextrins - Neostigmine $\cdot$ Neuromuscular block · Pharmacoeconomics - Residual paralysis ·

Rocuronium $\cdot$ Sugammadex

C. Meistelman $(\bowtie) \cdot$ T. Fuchs-Buder

Department of Anesthesiology, Hopital de Brabois, rue du Morvan, 54500 Vandoeuvre, France

e-mail: c.meistelman@chu-nancy.fr

T. Fuchs-Buder

e-mail: t.fuchs-buder@chu-nancy.fr

J. Raft

Department of Anesthesiology, Centre Alexis Vautrin,

Avenue de Bourgogne, 54500 Vandoeuvre, France

e-mail: j.raft@nancy.unicancer.fr

\section{Introduction}

Residual effects of neuromuscular block are now well identified. They can induce unpleasant effects such as muscle weakness but they can also have significant clinical consequences and can result in critical respiratory events (CRE) [1, 2•]. Even $2 \mathrm{~h}$ after a single bolus dose of any intermediate-acting non depolarizing muscle relaxant (NDMR), one-third of the patients have a train-of-four (TOF) ratio less than 0.9 [3]. Until recently, the action of NDMR could only be reversed by anticholinesterase drugs which temporarily inactivate acetylcholinesterase and increase the amounts of acetylcholine at the postsynaptic membrane. However, their use has several pitfalls due to their muscarinic effects, their relatively slow onset or the inability to reverse deep levels of neuromuscular block [4]. The release of sugammadex since 2009 in Europe after its approval in July 2008 provides a new approach in the management of neuromuscular blockade during surgery and the prevention of residual paralysis at the end of the case.

\section{Pharmacological Properties of Sugammadex}

Cyclodextrins comprise a family of cyclic oligosaccharides, which have been previously used to formulate different agents used in anesthesia including propofol, etomidate, bupivacaine, sufentanil or intranasal midazolam. Sugammadex is a modified $\gamma$ cyclodextrin specifically designed to encapsulate rocuronium and chemically similar aminosteroidal muscle relaxants such as vecuronium [5]. The underlying mechanism of action is new and differs completely from that of acetylcholinesterase inhibitors. When sugammadex is introduced into the blood, the free 
molecules of rocuronium in plasma which are in equilibrium with the tissues are almost immediately captured by the sugammadex molecules, and the plasma free rocuronium concentration decreases very rapidly [6]. This creates a gradient of rocuronium between tissue and plasma, with rocuronium molecules moving out of the tissue and into plasma, where they are encapsulated by free sugammadex molecules. The diffusion of sugammadex into the tissues and formation of complexes at the neuromuscular junction remains to be discussed. Following administration of sugammadex, the concentration of free rocuronium decreases rapidly in the plasma but the total rocuronium plasma concentration (free and bound to sugammadex) increase rapidly [7]. Subsequently, the complex will be rapidly filtered by the glomerulus and eliminated through the kidney. Sugammadex has no direct effect on cholinergic transmission. It is considered as a selective relaxant binding drug (SRBA). Sugammadex does not exhibit intrinsic biological activity.

Sugammadex selectively reverses steroidal NDMR, particularly rocuronium but also vecuronium. Its selectivity for steroidal NDMR over atracurium or succinylcholine is due to the size of its inner cavity and its structural complementarity with the right hydrophobic steroidal skeleton. It does not have any affinity for more than 40 drugs that may be used during anesthesia (hypnotics, analgesics, antibiotics, cardiovascular drugs). Affinity for cortisone, hydrocortisone, aldosterone has been extensively studied because sugammadex binds strongly to steroidal NDMR; affinity for these agents is 120 -fold less than for rocuronium. Affinity for atropine, verapamil, and ketamine is 400-700-fold lower than for rocuronium. Among many molecules studied, toremifene and flucloxacillin are the only molecules known to displace rocuronium or vecuronium from sugammadex.

Initial studies in adult patients have confirmed that sugammadex, administered at reappearance of the second twitch (T2) of the TOF, reversed rocuronium-induced neuromuscular block $(0.6 \mathrm{mg} / \mathrm{kg})$ in a dose-dependant manner. At doses of sugammadex at or above $2.0 \mathrm{mg} / \mathrm{kg}$ recovery occurred within 3 min without any sign of recurarisation [8-10]. When compared with neostigmine for reversal of neuromuscular block at reappearance of four TOF responses, it has been shown that a TOF ratio of 0.9 was obtained in approximately 2 min with sugammadex compared to 17 min using neostigmine [11]. Moreover, $2-4 \mathrm{mg} / \mathrm{kg}$ sugammadex, when given at reappearance of $\mathrm{T} 2$ in prolonged rocuronium-induced block $(>2 \mathrm{~h})$, effectively reversed rocuronium [12]. It was also shown that there were no differences in the time taken to reach a TOF ratio of 0.9 after anesthesia maintained with halogenated agents when compared with propofol [13]. Although sugammadex was developed to antagonize rocuronium- induced block; it is also effective in reversing vecuronium $(0.1 \mathrm{mg} / \mathrm{kg})$ [14]. When given at reappearance of $\mathrm{T} 2$, recovery to a TOF ratio of 0.9 was obtained in 2.3 and $1.5 \mathrm{~min}$ following 2.0 and $4.0 \mathrm{mg} / \mathrm{kg}$ of sugammadex, respectively [15].

During a deeper level of block (less than two responses to TOF stimulation), neither rocuronium nor vecuronium can be reversed satisfactorily within a short period of time using neostigmine. Profound neuromuscular block (Post-tetanic count of 1 or 2) can be rapidly and safely reversed with sugammadex in humans. With 4 or $8 \mathrm{mg} / \mathrm{kg}$, a TOF ratio of 0.9 could be obtained in $3.3 \mathrm{~min}$ (range $2.2-4.7 \mathrm{~min}$ ) and $1.5 \mathrm{~min}$ (1-0 to $2.1 \mathrm{~min})$ respectively [10].

There are situations in which deep block must be reversed very rapidly, for example when tracheal intubation has failed. When given $3 \mathrm{~min}$ after $1.2 \mathrm{mg} / \mathrm{kg}$ rocuronium, $16 \mathrm{mg} / \mathrm{kg}$ sugammadex can completely reverse profound block in less than $3 \mathrm{~min}$ [16•]. In this setting, recovery with sugammadex is significantly faster than spontaneous recovery from succinylcholine.

\section{Sugammadex Versus Neostigmine: Is it Worth it?}

In 1954, Beecher and Todd suggested that the use of NDMRs could significantly increase the mortality rate during general anesthesia. These findings were likely due not only to the infrequent use of controlled ventilation in these patients, but also to residual paralysis and possible CRE after surgery [17]. Therefore, in the early 1960s Cecil Gray suggested the routine administration of $5 \mathrm{mg}$ neostigmine at the end of surgery to prevent residual paralysis, when long acting NMBA were used. For over 40 years anticholinesterases have been widely used to reverse neuromuscular block at the end of the surgical procedure (the most commonly employed being neostigmine).

Many studies have confirmed the efficiency of anticholinesterase agents in reversing neuromuscular block. Baillard et al. [18] have clearly demonstrated that the rate of residual paralysis in the recovery room had significantly decreased over 10 years by routine use on monitoring of neuromuscular block in association with administration of neostigmine when residual paralysis was detected. The rate of residual blockade as defined as a TOF ratio $<0.9$ decreased from 62 to $3 \%$, confirming the benefit of reversal in routine anesthetic practice. Similarly, in a study by Arbous et al. [19] in more than 850,000 patients in Holland, the investigators were able to demonstrate that the use of reversal agents at the end of the case was associated with significant decrease in morbidity and mortality (odd ratio: $0.10 ; 95 \%$ confidence interval: $0.032-0.314$ )

Therefore, the need for a new reversal agent with a completely different mode of action such as with sugammadex 
should be compared to current practice, which involves the use of conventional anticholinesterase agents.

Anticholinesterases in clinical practice (neostigmine, as well as edrophonium and pyridostigmine) have important limitations. There is the absolute need to use them in association with atropine or glycopyrrolate to avoid muscarinic side effects such as tachycardia and hypotension. The concomitant use of atropine induces its own side effects such as tachycardia, dry mouth and blurred vision. Therefore, neostigmine should be used with caution in patients with cardiovascular disease or severe asthma. A less evident limitation of neostigmine is its relatively slow onset of action. Increasing doses to shorten its onset is not a valuable option because neostigmine exhibits a ceiling effect for doses greater than $70 \mu \mathrm{g} / \mathrm{kg}$ because of the limited amount of acetylcholine at the neuromuscular junction. Moreover, recovery of less profound levels of neuromuscular block (at least two responses to TOF stimulation at the adductor pollicis) following neostigmine is not as fast as usually thought. Kopman et al. [20] demonstrated that when neostigmine was given at a TOF count of two during rocuronium- or cisatracurium-induced neuromuscular block, the TOF ratio reached only 0.76 and 0.72 , respectively, $10 \mathrm{~min}$ after administration. These findings were confirmed by Blobner et al. [21] who demonstrated that the median time to reach a TOF ratio of 0.9 from a TOF count of two following neostigmine administration was $18.5 \mathrm{~min}$. One major issue was the large interindividual variability; even 60 min after neostigmine administration less than $90 \%$ of the patients had reached a TOF ratio of 0.9. These findings have clinical consequences because it is now recognized that TOF ratios less than 0.9 are associated with adverse respiratory events, including reduced upper airway volumes, airway obstruction, hypoxemia events, and postoperative pulmonary complications [1]. The upper airway muscles are particularly sensitive to the effects of NDMR [22]. For example, upper esophageal tone is decreased and the incidence of aspiration is increased in subjects with TOF ratios less than 0.9 [23]. After giving neostigmine, there is a risk for the anesthetist to feel overconfident and to extubate the patient before a TOF ratio of 0.9 has been reached.

In the elderly patients, the time needed to achieve a TOF ratio of 0.9 does not differ significantly when compared with younger patients. As for any NDMR, this slightly slower onset of action in the elderly could be due to circulatory factors such as altered muscle perfusion or decreased cardiac output [24]. There are few data in pediatric patients. Plaud et al. [25•] demonstrated that sugammadex could be used safely at a dose of $2 \mathrm{mg} / \mathrm{kg}$ and that recovery times were similar in children and adolescents when compared with adults. Although there was a small number of infants studied, recovery time to obtain a 0.9 TOF ratio, after sugammadex, was rapid ranging from 0.6 to $3.7 \mathrm{~min}$.
There is another major limitation of neostigmine; it is effective in reversing neuromuscular block only after spontaneous recovery has started. Therefore, there has always been a clinical need for a reversal agent that can rapidly reverse neuromuscular block regardless of its depth. Jones et al. [26••] compared the efficacy of sugammadex versus neostigmine for reversal of a deep level of rocuronium-induced paralysis. Sugammadex or neostigmine was given at reappearance of 1-2 responses of the PTC, when no responses to standard TOF stimulation at the adductor pollicis could be detected. A TOF ratio of 0.9 was attained in 2.9 min with sugammadex versus $50.4 \mathrm{~min}$ in patients receiving neostigmine-glycopyrrolate. The most important finding was the reproducibility and the small range of recovery times when sugammadex is given; $97 \%$ of patients receiving sugammadex had a TOF ratio above 0.9 within 5 min of administration, whereas a large number of patients receiving neostigmine did not recover until 30-60 min following administration, and $23 \%$ did not recover to a TOF ratio of 0.9 until more than $60 \mathrm{~min}$ had elapsed. These results were confirmed by other studies, which have also confirmed the ineffectiveness of neostigmine for the reversal of deep neuromuscular block. Sabo et al. [27] found that after reversal at a PTC of 1 or more, a TOF ratio of 0.9 was reached at or before extubation in $96 \%$ of patients receiving sugammadex versus $39.5 \%$ of patients who received neostigmine.

This ability to reverse intense neuromuscular block very rapidly and reliably provides clinicians with the opportunity to maintain muscle relaxation until the end of the procedure. There are clinical situations where the surgeon needs complete relaxation of the patient until the end of the case (major abdominal or thoracic surgery, laparoscopic surgery), and where the anesthetist is reluctant to provide full paralysis because it will significantly delay recovery and turnover of patients in the operating room. With sugammadex, it is possible to maintain paralysis of the diaphragm and the abdominal wall muscles, which are resistant to the effects of NMBA [28-30] when compared with peripheral muscles such as the adductor pollicis, until completion of the surgical procedure. However, in this clinical scenario, the anesthetist will likely need to administer a larger dose of sugammadex ( 4 versus $2 \mathrm{mg} / \mathrm{kg}$ ). Therefore, the need for monitoring remains critical, since it is the only objective method of evaluating the depth of neuromuscular block and determining the dose of sugammadex that needs to be administered ( 2 or $4 \mathrm{mg} / \mathrm{kg}$ ) at the end of the case.

To summarize, the main advantages of sugammadex, when compared with neostigmine or edrophonium, are a significantly faster and more predictable recovery profile and the possibility (for the first time) of reversing efficiently and very rapidly deep levels of neuromuscular block (Fig. 1). Moreover, the use of inhalation anesthetics, 
Fig. 1 Compared therapeutic window for neostigmine and sugammadex during rocuronium-induced neuromuscular block
Therapeutic Range of Neostigmine and Sugammadex

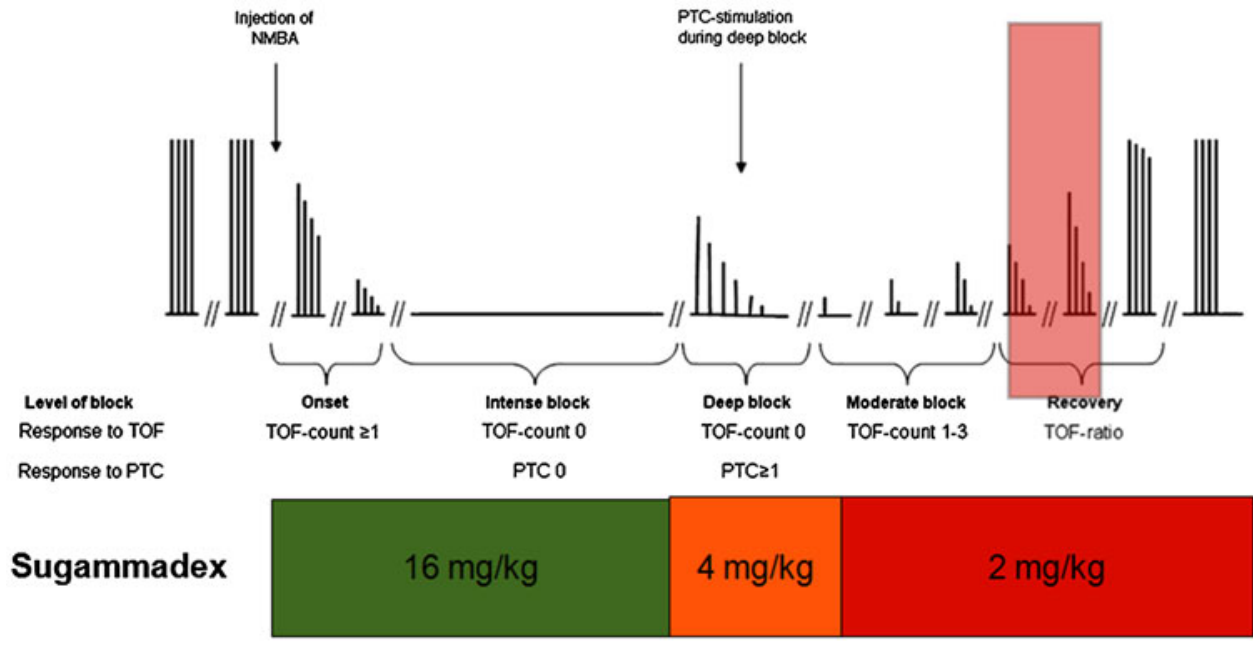

Neostigmine

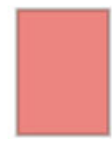

which usually prolong neuromuscular recovery times, have no impact on the efficacy of sugammadex.

\section{Will Sugammadex Change Our Practice of Anesthesia?}

NDMRs are used routinely for many surgical procedures because they provide adequate abdominal muscular relaxation. Some authors have suggested that NDMRs do not need to be used routinely, for example, during retroperitoneal or retropubic surgery. A prospective controlled study has demonstrated that NDMRs (vecuronium) significantly decreased the rate of unacceptable operating conditions in patients undergoing retropubic surgery, even if halogenated agents were used for maintenance of anesthesia. Moreover, the surgeons found that abdominal muscle relaxation, as estimated by clinical judgement, increased with increasing doses of vecuronium [31]. The diaphragm and the abdominal wall muscles are the most resistant muscles of the body to NDMR. In some cases, the surgeon may complain about patient movement because the diaphragm has already started its recovery or the patient is coughing, whereas the peripheral muscles such as the adductor pollicis were still fully paralyzed with no response to TOF stimulation at the adductor pollicis [29, 32]. Anesthesiologists have been reluctant to maintain deep levels of neuromuscular block to the end of the surgical procedure because until recently it was impossible to reverse deep neuromuscular block. With the introduction of sugammadex, this challenging situation should not be a problem anymore. It is now possible to fully paralyze the diaphragm and the abdominal wall muscles with greater doses of steroidal NDMR and to maintain this deep block until the closure or the removal of the last device during laparoscopic surgery.

Now that anesthesiologists have access to a variety of drugs with a short offset times (desflurane, sevoflurane, propofol, remifentanil), it will also be possible to have a very precise control of neuromuscular block when steroidal NMBA are used to maintain relaxation and to obtain a rapid and reliable recovery from deep neuromuscular block.

\section{Pharmacoeconomics Considerations}

Compared with neostigmine or edrophonium (plus an anticholinergic agent), the costs for sugammadex are significantly higher. This direct costs must be balanced against the potential risks (and costs) of incomplete neuromuscular recovery, such as muscle weakness, adverse respiratory events, significant delays in meeting PACU discharge criteria and achieving PACU discharge.

Paton et al. [33•] were the first authors to study the costeffectiveness of sugammadex for the routine reversal of rocuronium- or vecuronium-induced neuromuscular block in UK hospitals. Using the results provided by the previous randomized controlled trials, they were able to demonstrate that sugammadex reduced the time to achieve a TOF ratio of 0.9 by $14-17$ min during a shallow block and by 47 and $61 \mathrm{~min}$ for rocuronium- and vecuronium-induced deep neuromuscular block (no response at the TOF). Taking into 
account the NHS Economic Evaluation Database (NHS EDD) and assuming that time saved in the OR has a value of $£ 4.44 / \mathrm{min}$, the authors were able to demonstrate that 2 or $4 \mathrm{mg} / \mathrm{kg}$ sugammadex was cost-effective for routine reversal of shallow and deep neuromuscular blockade (if reductions in recovery times were obtained in the operating room and enhanced recovery was associated with improvements in productivity and more efficient use of staff members).

Chambers et al. [34] published an economic assessment on the use of sugammadex for reversal when given $3 \mathrm{~min}$ following rapid sequence induction $(1.2 \mathrm{mg} / \mathrm{kg}$ rocuronium). They investigated the economic benefits of reversing $1.2 \mathrm{mg} / \mathrm{kg}$ rocuronium with $16 \mathrm{mg} / \mathrm{kg}$ sugammadex in comparison with the spontaneous recovery after $1 \mathrm{mg} / \mathrm{kg}$ succinylcholine. The assessment was performed taking into account various assumptions such as the value of any reduction in recovery time, the likelihood of a "cannot intubate, cannot ventilate" event (CICV), the age of the patient and the length of the procedure. In accordance with the UK National Institute of Health (NIS), and the value of a quality-adjusted life year of GBP 20,000 (UDS 32,000) they assumed that, with an incidence of $1 \%$ of "cannot intubatecannot ventilate" in a group of 60-year-old patients, sugammadex could become cost-effective if it prevented at least one death for every 1,942 patients. Furthermore, during short or long procedures, if the saved recovery time was achieved in the operating room, then the value of saved time was sufficient in itself for sugammadex to appear cost-effective, regardless of any reduction in mortality risk. However, as pointed out by the authors, their cost effectiveness models are defined on the basis of several assumptions (UK cost for example), which may have an impact on the reliability of their model and its use in different countries

Sugammadex was introduced more recently in Australia. Following its introduction, at the Royal Perth hospital, the use of benzylisoquinoline NDMR decreased significantly, while the use of rocuronium and even vecuronium increased. During the same time period, the use of neostigmine was reduced by nearly $50 \%$. The cost of reversal was increased, but a reduction in the median duration of hospital stay was observed (78 h in 2010 versus $73 \mathrm{~h}$ in 2011; $p<0.05)$. The authors hypothesized that the reduction in hospital stay could fully offset the observed increased costs of sugammadex [35]. The unrestricted use of sugammadex was also evaluated in a tertiary teaching hospital. The authors observed a significant reduction in anesthetic time from 143 to $120 \mathrm{~min}$ [36]. The reduction in time between the last rocuronium dose and reversal (approximately $30 \mathrm{~min}$ ) was attributed to a greater willingness to maintain deep levels of neuromuscular block

Raft et al. [37], in France, utilized a different approach. The authors studied the consequences of the introduction of sugammadex in a cancer center performing approximately 2,400 major abdominal surgical procedures under general anesthesia per year. The staff members had unlimited access to both neostigmine and sugammadex in their daily clinical practice. However there was a strict policy of neuromuscular monitoring for all the patients receiving a NDMR. Moreover, the dosing was strictly based on data provided by neuromuscular monitoring: $2 \mathrm{mg} / \mathrm{kg}$ for shallow levels of neuromuscular block, $4 \mathrm{mg} / \mathrm{kg}$ for deep levels of block and $16 \mathrm{mg} / \mathrm{kg}$ for immediate rescue reversal. As in previous studies, they observed an increase in the use of rocuronium $(+426 \%)$, whereas the use of atracurium $(-62 \%)$, cisatracurium $(-60 \%)$ and succinylcholine decreased $(-16 \%)$. Simultaneously, the use of neostigmine was decreased $(-59 \%)$ and the overall cost for sugammadex was appoximately $24,000 €$ for the first year after its introduction in the hospital. Taking into account the total number of patients under general anesthesia in their institution $(3,355)$, they were able to demonstrate that the total anesthesia costs per case increased by about $8.22 €$ [37]. As suggested for other anesthetic agents such as desflurane, the authors concluded that this increase in costs should be counterbalanced by a faster turnover in the operating room and a shorter duration of stay in the PACU.

It would be tempting to use lower doses of sugammadex to decrease costs, particularly when there are already four responses to TOF stimulation or a measurable TOF ratio. Schaller et al. [38] have calculated the average dose of sugammadex to completely reverse a residual block corresponding to a TOF ratio of 0.5 . Sugammadex, $0.22 \mathrm{mg} / \mathrm{kg}$, was effective in reversing a TOF ratio of 0.5 to a TOF ratio of 0.9 or higher in an average time of $2 \mathrm{~min}$. Within $5 \mathrm{~min}$, $95 \%$ of patients could achieve a TOF ratio of 0.9 ; however, due to the mechanism of action of sugammadex, the use of low doses could lead to reappearance of neuromuscular block after an initial and successful recovery. This risk was confirmed by Eleveld et al. [39], who described the reappearance of neuromuscular block following initial recovery when using doses of sugammadex that were too low. It is likely that when sugammadex is not administered at a sufficient dose, it can initially form complexes with rocuronium in blood and initiate recovery. However, the dose will be insufficient to sustain redistribution of rocuronium from the neuromuscular junction to blood causing a reappearance of residual paralysis.

\section{Side Effects}

Because sugammadex does not act as neostigmine or edrophonium (inhibition of acetylcholinesterase and indirect action on receptors), but by encapsulation in the plasma, it is not expected to have a side effect profile 
Table 1 Recommended doses of sugammadex depending of the degree of neuromuscular blockade or the clinical situation

\begin{tabular}{llc}
\hline NDMR & Type of block & Dose $(\mathrm{mg} / \mathrm{kg})$ \\
\hline Rocuronium, vecuronium & Shallow & 2 \\
Rocuronium, vecuronium & Deep & 4 \\
Rocuronium & CICV & 16 \\
\hline
\end{tabular}

Shallow level of neuromuscular block: $2-4$ responses at the TOF at the adductor pollicis

Deep level of neuromuscular block: less than five responses at the PTC at the adductor pollicis

$C I C V$ cannot intubate, cannot ventilate

similar to the anticholinesterase agents. Most of the related side effects observed in phase II and III studies were nonspecific, including hypotension, movement, coughing, dry mouth or nausea. Prolongation of the corrected QT interval has been described but with the same rate reported in the placebo group. QT prolongation can be observed with several anaesthetic agents; therefore, its significance was highly questionable. Dahl et al. [40] have confirmed the lack of cardiovascular effects of both 2 and $4 \mathrm{mg} / \mathrm{kg}$ doses of sugammadex in patients with cardiovascular disease undergoing non cardiac surgery.

The package insert of sugammadex has been recently supplemented with the notification of a potential prolongation of clotting times in the first min following its administration without any documented clinical consequences. In an observational study, Raft et al. [41] investigated coagulation parameters before, $1 \mathrm{~h}$ after sugammadex administration and on postoperative day 1 ; these included clinical bleeding, hemoglobin concentration, hematocrit, activated partial thromboplastin time (aPTT) and prothrombin time (PT). One hundred and forty-two patients scheduled for major abdominal cancer surgery and at risk of surgical bleeding were studied. They did not find any significant differences between the control group (no sugammadex) and the groups receiving either 2 or $4 \mathrm{mg} / \mathrm{kg}$ sugammadex in terms of clinical bleeding. Sugammadex administration was not associated with longer clotting times or decreased hemoglobin concentrations.

Any NDMR can cause anaphylactic reactions because quaternary ammonium ions are suggested to be the allergenic determinants. In most of the cases cross reactivity can be observed even between steroidal and benzylisoquinoline NDMRs [42•]. The use of sugammadex to capture rocuronium and to be an adjunct in the management of rocuronium-induced anaphylactic complications has been described. There are a few clinical cases where sustained hemodynamic improvement (increase in blood pressure and normalization of heart rate) was observed during a rocuronium anaphylactic event after administration of sugammadex. Baldo has suggested that sugammadex could eventually interact with mast cells. However, there is not yet enough scientific evidence to recommend sugammadex as the treatment of choice during anaphylactic reaction due to steroidal NMBA.

\section{Conclusion}

Sugammadex is a very exciting drug because, for the first time, we have a molecule that can effectively and rapidly reverse any level of vecuronium- or rocuronium-induced neuromuscular block when given at the appropriate dose. Moreover, the variability of reversal times is greatly reduced. The use of sugammadex can improve the safety and ease of management of neuromuscular block in the perioperative period. It is now possible to maintain neuromuscular block until the end of the surgical procedure with little risk of incomplete neuromuscular recovery. Based on the available studies, it is recommended to use $2.0 \mathrm{mg} / \mathrm{kg}$ for reversing a shallow rocuronium block. Deep rocuronium-induced block can be easily and rapidly reversed with $4 \mathrm{mg} / \mathrm{kg}$ sugammadex. This dose is not associated with any recurrence of block. A dose of $16 \mathrm{mg} / \mathrm{kg}$ can efficiently and rapidly reverses rocuronium $3 \mathrm{~min}$ after its administration (Table 1). It is now obvious that the introduction of sugammadex into clinical practice has increased our therapeutic options. Should we withdraw neostigmine from our clinical use? Certainly not, because it is the only reversal agent effective in antagonizing benzylisoquinoline NDMR. Moreover, it use can still be considered for reversal of low levels of residual paralysis such as a TOF ratio above 0.4 [43].

Disclosure Claude Meistelman has received compensation from MSD for serving on an advisory board and for lectures including service on speakers bureaus. Thomas Fuchs-Buder has received compensation from Merck for his service on a board and for lectures including service on speakers bureaus. Julien Raft has received compensation from Merck for his service as a consultant, for lectures including service on speakers bureaus, for the development of educational presentations, and for travel/accommodations/meeting expenses incurred through the American Society of Anesthesiologists Annual Meeting 2012.

\section{References}

Papers of particular interest, published recently, have been highlighted as:

- Of importance

-• Of major importance

1. Murphy GS, Szokol JW, Marymont JH, Greenberg SB, Avram MJ, Vender JS. Residual neuromuscular blockade and critical respiratory events in the postanesthesia care unit. Anesth Analg. 2008;107:130-7. 
2. - Murphy GS, Szokol JW, Avram MJ, Greenberg SB, Marymont JH, Vender JS, Gray J, Landry E, Gupta DK: Intraoperative acceleromyography monitoring reduces symptoms of muscle weakness and improves quality of recovery in the early postoperative period. Anesthesiology. 2011;115:946-54 This study highlights the use of objective monitoring of neuromuscular block to prevent residual paralysis in the PACU.

3. Debaene B, Plaud B, Dilly MP, Donati F. Residual paralysis in the PACU after a single intubating dose of nondepolarizing muscle relaxant with an intermediate duration of action. Anesthesiology. 2003;98:1042-8.

4. Plaud B, Debaene B, Donati F, Marty J. Residual paralysis after emergence from anesthesia. Anesthesiology. 2010;112:1013-22.

5. Zhang MQ. Drug-specific cyclodextrins: the future of rapid neuromuscular block reversal? Drugs Future. 28;28:347-54.

6. Bom A, Bradley M, Cameron K, Clark JK, Van Egmond J, Feilden H, MacLean EJ, Muir AW, Palin R, Rees DC, Zhang MQ. A novel concept of reversing neuromuscular block: chemical encapsulation of rocuronium bromide by a cyclodextrinbased synthetic host. Angew Chem Int Ed Engl. 2002;41:266-70.

7. Epemolu O, Bom A, Hope F, Mason R. Reversal of neuromuscular blockade and simultaneous increase in plasma rocuronium concentration after the intravenous infusion of the novel reversal agent Org 25969. Anesthesiology. 2003;99:632-7.

8. Sorgenfrei IF, Norrild K, Larsen PB, Stensballe J, Ostergaard D, Prins ME, Viby-Mogensen J. Reversal of rocuronium-induced neuromuscular block by the selective relaxant binding agent sugammadex: a dose-finding and safety study. Anesthesiology. 2006;104:667-74.

9. Gijsenbergh F, Ramael S, Houwing N, van Iersel T. First human exposure of Org 25969, a novel agent to reverse the action of rocuronium bromide. Anesthesiology. 2005;103:695-703.

10. Groudine SB, Soto R, Lien C, Drover D, Roberts K. A randomized, dose-finding, phase II study of the selective relaxant binding drug, sugammadex, capable of safely reversing profound rocuronium-induced neuromuscular block. Anesth Analg. 2007; 104:555-62.

11. Sacan O, White PF, Tufanogullari B, Klein K. Sugammadex reversal of rocuronium-induced neuromuscular blockade: a comparison with neostigmine-glycopyrrolate and edrophoniumatropine. Anesth Analg. 2007;104:569-74.

12. Shields M, Giovannelli M, Mirakhur RK, Moppett I, Adams J, Hermens Y. Org 25969 (sugammadex), a selective relaxant binding agent for antagonism of prolonged rocuronium-induced neuromuscular block. Br J Anaesth. 2006;96:36-43.

13. Vanacker BF, Vermeyen KM, Struys MM, Rietbergen H, Vandermeersch E, Saldien V, Kalmar AF, Prins ME. Reversal of rocuronium-induced neuromuscular block with the novel drug sugammadex is equally effective under maintenance anesthesia with propofol or sevoflurane. Anesth Analg. 2007;104:563-8.

14. Duvaldestin P, Kuizenga K, Saldien V, Claudius C, Servin F, Klein J, Debaene B, Heeringa M. A randomized, dose-response study of sugammadex given for the reversal of deep rocuroniumor vecuronium-induced neuromuscular blockade under sevoflurane anesthesia. Anesth Analg. 2010;110:74-82.

15. Suy K, Morias K, Cammu G, Hans P, van Duijnhoven WG, Heeringa $\mathrm{M}$, Demeyer I. Effective reversal of moderate rocuronium- or vecuronium-induced neuromuscular block with sugammadex, a selective relaxant binding agent. Anesthesiology. 2007;106:283-8.

16. - Lee C, Jahr JS, Candiotti KA, Warriner B, Zornow MH, Naguib M: Reversal of profound neuromuscular block by sugammadex administered three minutes after rocuronium: a comparison with spontaneous recovery from succinylcholine. Anesthesiology. 2009;110:1020-5 This study demonstrates the interest of sugammadex for early reversal and its potential interest in the "cannot intubate cannot ventilate" situation.
17. Beecher HK, Todd DP. A study of the deaths associated with anesthesia and surgery: based on a study of 599, 548 anesthesias in ten institutions 1948-1952, inclusive. Ann Surg. 1954;140:2-35.

18. Baillard C, Clec'h C, Catineau J, Salhi F, Gehan G, Cupa M, Samama CM. Postoperative residual neuromuscular block: a survey of management. Br J Anaesth. 2005;95:622-6.

19. Arbous MS, Meursing AE, van Kleef JW, de Lange JJ, Spoormans HH, Touw P, Werner FM, Grobbee DE. Impact of anesthesia management characteristics on severe morbidity and mortality. Anesthesiology. 2005;102:257-68.

20. Kopman AF, Zank LM, Ng J, Neuman GG. Antagonism of cisatracurium and rocuronium block at a tactile train-of-four count of 2: should quantitative assessment of neuromuscular function be mandatory? Anesth Analg. 2004;98:102-6.

21. Blobner M, Eriksson LI, Scholz J, Motsch J, Della RG, Prins ME. Reversal of rocuronium-induced neuromuscular blockade with sugammadex compared with neostigmine during sevoflurane anaesthesia: results of a randomised, controlled trial. Eur J Anaesthesiol. 2010;27:874-81.

22. Eikermann M, Vogt FM, Herbstreit F, Vahid-Dastgerdi M, Zenge MO, Ochterbeck C, de Greiff A, Peters J. The predisposition to inspiratory upper airway collapse during partial neuromuscular blockade. Am J Respir Crit Care Med. 2007;175:9-15.

23. Eriksson LI, Sundman E, Olsson R, Nilsson L, Witt H, Ekberg O, Kuylenstierna R. Functional assessment of the pharynx at rest and during swallowing in partially paralyzed humans: simultaneous videomanometry and mechanomyography of awake human volunteers. Anesthesiology. 1997;87:1035-43.

24. McDonagh DL, Benedict PE, Kovac AL, Drover DR, Brister NW, Morte JB, Monk TG. Efficacy, safety, and pharmacokinetics of sugammadex for the reversal of rocuronium-induced neuromuscular blockade in elderly patients. Anesthesiology. 2011;114:318-29.

25. • Plaud B, Meretoja O, Hofmockel R, Raft J, Stoddart PA, van Kuijk JH, Hermens Y, Mirakhur RK: Reversal of rocuroniuminduced neuromuscular blockade with sugammadex in pediatric and adult surgical patients. Anesthesiology. 2009; 110: 284-94 The first study providing data on the use and the efficacy of sugammadex in pediatric patients.

26. • Jones RK, Caldwell JE, Brull SJ, Soto RG: Reversal of profound rocuronium-induced blockade with sugammadex: a randomized comparison with neostigmine. Anesthesiology. 2008; 109: 816-24 This study highlights the efficacy and rapidity of sugammadex to reverse deep levels of neuromuscular block.

27. Sabo D, Jones RK, Berry J, Sloan T, Chen J, Morte JB, Groudine SB. Residual neuromuscular blockade at extubation: a randomized comparison of sugammadex and neostigmine reversal of rocuronium-induced blockade in patients undergoing abdominal surgery. J Anesth Clinic Res. 2011;2:140. doi:10,4172/21556148.1000140.

28. Pansard JL, Chauvin M, Lebrault C, Gauneau P, Duvaldestin P. Effect of an intubating dose of succinylcholine and atracurium on the diaphragm and the adductor pollicis in humans. Anesthesiology. 1987;67:326-30.

29. Donati F, Meistelman C, Plaud B. Vecuronium neuromuscular blockade at the diaphragm, the orbicularis oculi, and adductor pollicis muscles. Anesthesiology. 1990;73:870-5.

30. Kirov K, Motamed C, Dhonneur G. Differential sensitivity of abdominal muscles and the diaphragm to mivacurium: an electromyographic study. Anesthesiology. 2001;95:1323-8.

31. King M, Sujirattanawimol N, Danielson DR, Hall BA, Schroeder DR, Warner DO. Requirements for muscle relaxants during radical retropubic prostatectomy. Anesthesiology. 2000;93:1392-7.

32. Plaud B, Debaene B, Donati F. The corrugator supercilii, not the orbicularis oculi, reflects rocuronium neuromuscular 
blockade at the laryngeal adductor muscles. Anesthesiology. 2001;95:

96-101.

33. - Paton F, Paulden M, Chambers D, Heirs M, Duffy S, Hunter JM, Sculpher M, Woolacott N: Sugammadex compared with neostigmine/glycopyrrolate for routine reversal of neuromuscular block: a systematic review and economic evaluation. Br J Anaesth. 2010; 105:558-67 The first pharmacoeconomics study on sugammadex for routine reversal.

34. Chambers D, Paulden M, Paton F, Heirs M, Duffy S, Hunter JM, Sculpher M, Woolacott N. Sugammadex for reversal of neuromuscular block after rapid sequence intubation: a systematic review and economic assessment. Br J Anaesth. 2010;105:568-75.

35. Ledowski T, Hillyard S, Kozman A, Johnston F, Gillies E, Greenaway M, Kyle BC. Unrestricted access to sugammadex: impact on neuromuscular blocking agent choice, reversal practice and associated healthcare costs. Anaesth Intensive Care. 2012;40: 340-3.

36. Watts RW, London JA, van Wijk RM, Lui YL. The influence of unrestricted use of sugammadex on clinical anaesthetic practice in a tertiary teaching hospital. Anaesth Intensive Care. 2012;40: 333-9.

37. Raft J, Chenot ED, Longrois D, Meistelman C. Analysis of neuromuscular blocking drugs and sugammadex expenses, 1 year after its introduction into routine clinical practice. Ann fr Anesth Reanim. 2011;30:758-9.
38. Schaller SJ, Fink H, Ulm K, Blobner M. Sugammadex and neostigmine dose-finding study for reversal of shallow residual neuromuscular block. Anesthesiology. 2010;113:1054-60.

39. Eleveld DJ, Kuizenga K, Proost JH, Wierda JM. A temporary decrease in twitch response during reversal of rocuroniuminduced muscle relaxation with a small dose of sugammadex. Anesth Analg. 2007;104:582-4.

40. Dahl V, Pendeville PE, Hollmann MW, Heier T, Abels EA, Blobner M. Safety and efficacy of sugammadex for the reversal of rocuronium-induced neuromuscular blockade in cardiac patients undergoing noncardiac surgery. Eur J Anaesthesiol. 2009;26:874-84.

41. Raft J, Harter V, Guerci P, Fuchs-Buder T., Meistelman, C. Biological evaluation of sugammadex on hemostasis and bleeding. Anesthesiology. 2012; A1009.

42. - Dewachter P, Mouton-Faivre C, Emala CW: Anaphylaxis and anesthesia: controversies and new insights. Anesthesiology. 2009; 111:1141-50 A comprehensive general review on anaphylaxis during anesthesia and the role of NDMR.

43. Fuchs-Buder T, Meistelman C, Alla F, Grandjean A, Wuthrich Y, Donati F. Antagonism of low degrees of atracurium-induced neuromuscular blockade: dose-effect relationship for neostigmine. Anesthesiology. 2010;112:34-40. 